2017-03

\title{
Public or private religiosity: which Is protective for adolescent substance use and by w...
}

This work was made openly accessible by BU Faculty. Please share how this access benefits you. Your story matters.

\begin{tabular}{|l|l|}
\hline Version & \\
\hline Citation (published version): & $\begin{array}{l}\text { Christopher P. Salas-Wright, Michael G. Vaughn, Brandy R. Maynard, } \\
\text { Trenette T. Clark, Susanna Snyder. 2017. "Public or Private } \\
\text { Religiosity: Which Is Protective for Adolescent Substance Use and by } \\
\text { What Pathways?." Youth \& Society, v. 49, Issue 2, pp. 228-253. }\end{array}$ \\
\hline
\end{tabular}

https://hdl.handle.net/2144/26124

Boston University 
Running Head: PUBLIC OR PRIVATE RELIGIOSITY?

\begin{abstract}
While it is well understood that adolescent religiosity is associated with the use and abuse of licit and illicit substances, few studies have revealed the pathways through which religiosity buffers youth against involvement in such behavior. The aim of this study is to examine the complexity of the relationships between religiosity, sensation seeking, injunctive norms, and adolescent substance use. Using a national sample of adolescents $(\mathrm{N}=18,614)$, negative binomial regression and path analysis were employed to examine the various components of the relationship between religiosity and the use of cigarettes, alcohol, and marijuana. Results indicate that private religiosity moderates the relationship between key risk factors and substance use. Public and private religiosity were associated with tolerant injunctive substance use norms which, in turn, were associated with substance use. Implications for research and theory related to religiosity and adolescent substance use are discussed.
\end{abstract}

Keywords: religiosity, substance use, sensation seeking, injunctive norms, adolescence 
PUBLIC OR PRIVATE RELIGIOSITY?

\section{Public or Private Religiosity: Which is Protective for Adolescent Substance Use and by What Pathways?}

Empirical research has consistently found religiosity to be inversely related to the use and abuse of licit and illicit substances among youth (Koenig, King, \& Carson, 2012; Salas-Wright, Hernandez, Maynard, Saltzman, \& Vaughn, 2014; Stone, Becker, Huber, \& Catalano, 2012; Yonker, Schnabelrauch, \& DeHaan, 2012). Although studies often examine religiosity as a unidimensional construct, research and theory suggest that religiosity is perhaps best understood as a multifaceted construct comprised of both public and private components (Allport \& Ross, 1967; Good \& Willoughby, 2006). Public religiosity typically refers to the frequency of religious service attendance or the degree of participation of adolescents in religiously-affiliated youth groups. Private religiosity, sometimes referred to as religious salience, tends to be conceptualized in terms of the intrinsic, or internalized, religious beliefs held by adolescents in regards to the importance of religious faith or religious involvement. Although a degree of inter-religious and inter-denominational differences have been identified (Fischer, 2010), in general, young people who report higher levels of public religious involvement and greater levels of private, or intrinsic, religiosity tend to be less likely than their peers to use tobacco (Longest \& Vaisey, 2008), alcohol (Hodge, Marsiglia, \& Nieri, 2011), marijuana (Ulmer, Desmond, Jang, \& Johnson, 2012), and a variety of other illicit substances (Salas-Wright, Vaughn, Hodge, \& Perron, 2012). Given that the vast majority of American adolescents report religious service attendance (Hardie, Pearce, \& Denton, 2013; Smith, Faris, Denton, \& Regnerus, 2003) and, importantly, that many do so out of their own interest in religion (Smith \& Denton, 2005), the potential protective effects of public and private religiosity and associated dynamic relationships deserve greater empirical attention. 
PUBLIC OR PRIVATE RELIGIOSITY?

A plethora of studies have documented the main-effects relationship between religiosity and adolescent substance use, and a robust body of literature has identified religiosity in general as a promotive and protective factor for adolescent substance use and abuse (Hodge et al., 2011; Longest \& Vaisey, 2008; Jang \& Johnson, 2011; Marsiglia, Kulis, Nieri, \& Parsai, 2005; SalasWright et al., 2012; Ulmer, Desmond, Jang, \& Johnson, 2010; Ulmer et al., 2012). Notably, however, research into the unique associations between public religiosity, private religiosity, and adolescent risk behavior suggests that an important degree of nuance can be observed in terms of the various expressions of religiosity. Indeed, some studies have identified differential outcomes in which only one component of religiosity - sometimes private, sometimes public - functions to protect against particular manifestations of adolescent problem behavior (Good \& Willoughby, 2006; Nonnemaker, McNeely, \& Blum, 2003; Salas-Wright, Olate, \& Vaughn, 2013a; SalasWright, Olate, \& Vaughn, 2013b). Other studies, although limited small in number, have identified null and negative effects between religiosity and risk behavior among samples drawn from particular regions of the United States (Stark, 1996) and high-risk populations (Topalli, Brezina, \& Bernhardt, 2012). Additionally, some uncertainty exists in terms of the pathways through which public and private religiosity are associated with substance use. More precisely, less is understood in terms of: (1) the ways in which the distinct components of religiosity may serve to moderate the relationship between salient risk factors and adolescent substance use and (2) the factors that mediate the relationship between public and private religiosity and adolescent substance use.

In terms of moderation, prior research has indicated that religiosity can serve to buffer the relationship between a variety of risk factors and outcome pairs including peer risk behavior and adolescent substance use (Bahr \& Hoffman, 2008); peer influence and the use of alcohol and 


\section{PUBLIC OR PRIVATE RELIGIOSITY?}

marijuana (Desmond, Soper, \& Kraus, 2011); and exposure to community violence and substance abuse (Fowler, Ahmed, Tompsett, Jozefowicz-Simbeni, \& Toro, 2008). As for mediation, the bulk of the empirical research examining the mediating factors between religiosity and adolescent substance use is situated within the framework of social control (Hirschi, 1969; Regnerus, 2003). That is, most religiosity research begins not with the question of why youth are involved in substance use or other problem behaviors, but rather with examining what social forces inhibit youth from engaging in risky behavior (Hirschi \& Stark, 1969; Stark, 1996). Typically, studies examine the ways in which religiosity increases the likelihood of positive social bonding or the development of negative substance use beliefs that, in turn, can serve to buffer youth from involvement in substance use behaviors. Recent studies have found religiosity to be associated with important mediating factors such as negative substance use beliefs, prosocial beliefs, and prosocial peer bonding (Johnson, Sheets, \& Kristeller, 2008; D’Onofrio et al., 1999; Harris, 2011; Kim, 2003).

While much of the literature examining the relationship between religiosity and substance use and other externalizing behaviors is situated within the social control theoretical framework, available evidence and theory suggest an alternative pathway involving self-control. Self-control, the capacity to intentionally refrain from immediately gratifying behaviors, has been a central explanatory factor for criminal and externalizing behavior (DeLisi \& Vaughn, 2008; Gottfredson \& Hirschi, 1990). Indeed, several studies have found negative relationships between self-control and substance use in youth and adults (Longshore, Chang, Hsieh, \& Messina, 2004; Vaughn, Beaver, DeLisi, Perron, \& Schelbe, 2009; Wills, Sandy, \& Yaeger, 2002). A corpus of evidence suggests the importance of religious engagement in the enhancement of self-regulation and selfcontrol, which, in turn, has implications for adolescent involvement in externalizing behavior 


\section{PUBLIC OR PRIVATE RELIGIOSITY?}

and substance use (McCullough \& Willoughby, 2009). In the context of self-control theory, religion may be conceptualized as exerting an effect on deviant behavior by enhancing an individual's self-regulatory capacity. The enhancement of self-control by means of religious involvement might take place via cognitive and behavioral-driven pathways. With respect to a cognitive pathway, religious traditions often include behavioral proscriptions as well as communal narratives that speak to the importance of self-discipline, moral behavior, the capacity to control one's behavior, and view's on the acceptability of substance use and involvement other risk behaviors (Smith, 2003). In terms of a behavioral pathway, religious communities typically encourage the participation of individuals in frequent public religious services, involvement in regular, disciplined practices such as private prayer and meditation, and involvement in service and charitable giving (Smith \& Denton, 2005). These cognitive and behavioral components, if practiced routinely, may assist individuals in strengthening their capacity for self-control and self-regulation, thereby decreasing the likelihood of involvement in impulsive, risky, or criminal behavior. In this way, religiosity can be thought of as a naturally occurring form of cognitive behavioral treatment.

\section{Adolescent Substance Use in the U.S.}

Despite many adolescents expressing disapproval and other negative views of substance use, substantial proportions of adolescents report lifetime and regular substance use. For example, while the vast majority of U.S. high school seniors consider smoking to be a "dirty habit" (72.4\%) and more than half believe that becoming a smoker reflects "poor judgment" $(55.5 \%)$, more than two in five (46\%) U.S. high school students have smoked cigarettes in their lifetime, almost one in five have done so during the previous month (18.7\%), and one in ten high school seniors in the U.S. smoke daily (10.3\%) (CDC, 2010b; Johnston, O’Malley, Bachman, \& 


\section{PUBLIC OR PRIVATE RELIGIOSITY?}

Schulenberg, 2011). Similarly troublesome trends can be identified in terms of adolescent alcohol and marijuana use. While most U.S. high school seniors report disapproval of heavy drinking $(70.5 \%)$, approximately the same percentage $(72.5 \%)$ report having used alcohol in their lifetimes (Johnston et al, 2011). More than two in five adolescents report having used alcohol in the last month (41.8\%) and roughly one in four reports having recently engaged in binge drinking (24.2\%) (CDC, 2010a). Rates of adolescent marijuana use are slightly lower than those of adolescent alcohol use. Still, adolescent disapproval and use of marijuana models a similar pattern to cigarette and alcohol disapproval and use. Although roughly half of all high school seniors report disapproval of trying marijuana (54.8\%) (Johnston et al., 2011), 36.8\% report having used marijuana in their lifetime and roughly one in five $(22.6 \%)$ report having done so in the last month (CDC, 2010b).

Adolescent substance use and abuse are major public health issues in the lives of individuals, families, and communities across the U.S. (Ellickson, Tucker, \& Klein, 2003). Although rates of substance use among U.S. adolescents have decreased slightly over the last decade (CDC, 2010a), the involvement of adolescents in substance use behaviors remains disconcerting in light of the negative outcomes associated with use. The use and abuse of tobacco, alcohol, and marijuana are associated with a range of deleterious health outcomes, chemical dependency, psychological distress, neurocognitive and functional impairment, vehicular trauma, life-threatening illness, and involvement in externalizing behaviors such as delinquency and violence (Dunlop \& Romer, 2010; Gandini et al., 2008; Jacobus, Bava, CohenZio, Mahmood, \& Tapert, 2009; Johnston, O’Malley, Bachman, \& Schulenberg, 2011c; Krug, Mercy, Dahlberg, \& Zwi, 2002; Rehm, Gmel, Sempos, \& Trevisan, 2003; Vaughn, Freedenthal, 
PUBLIC OR PRIVATE RELIGIOSITY?

Jenson, \& Howard, 2007; Vaughn, Salas-Wright, \& Maynard, 2013; White, Loeber, \& Farrington, 2008).

\section{Psychosocial Risk Factors for Substance Use}

While a wide variety of risk and protective factors have been identified in the empirical literature (Weinberg, 2001; Hawkins, Catalano, \& Miller, 1992), sensation seeking and injunctive norms are particularly important risk and protective factors in explaining adolescent substance use. Indeed, both the strength of the relationship between these two variables and substance use among adolescents and the consistency by which they are identified as salient factors in relation to substance use suggest that they are key individual-level factors for investigation (Hittner \& Swickert, 2006; O’Connor, Fite, Nowlin, \& Colder, 2007). Moreover, as illustrated in Figure 1, sensation seeking and injunctive norms can be conceptualized as factors profoundly interrelated with private and public religiosity, and adolescent substance use. For instance, given the links between religiosity and beliefs about the morality of substance use during adolescence, tolerant injunctive norms might mediate the relationship between private and public religiosity and substance use. Similarly, private and public religiosity might function to dampen the relationship between sensation seeking and tolerant injunctive norms among youth. Nevertheless, it is reasonable to hypothesize that sensation seeking as well as private and public religiosity may exert a direct effect on substance use.

\section{*** INSERT FIGURE 1 ABOUT HERE ***}

Sensation seeking. Sensation seeking refers to the tendency of individuals to seek out risky, dangerous, or novel experiences that could potentially lead to undesirable outcomes such as serious injury, legal consequences, or death (Zuckerman, 1979, 1994). Sensation seeking has consistently been identified as a risk factor for adolescent substance use initiation and abuse as 


\section{PUBLIC OR PRIVATE RELIGIOSITY?}

well as a variety of other high-risk behaviors (Hittner \& Swickert, 2006). Given that religious involvement has been noted as instrumental in adolescent development, particularly the development of social inhibitory factors such as self-regulation and self-control (McCullough \& Willoughby, 2009), prosocial bonding and moral beliefs about risk behavior (Johnson et al, 2008; D’Onofrio et al., 1999), and adolescent network closure (Smith, 2003), it is reasonable to hypothesize that public and private religiosity might effectively attenuate the association between sensation seeking and substance use approval and involvement.

Tolerant injunctive norms. Injunctive norms refer to the perception of individuals that particular behaviors tend to be socially acceptable or unacceptable (Shultz et al., 2007). Tolerant injunctive norms towards substance use refer to the belief that substance use is socially acceptable. Such tolerant beliefs have been found to be strongly associated with substance use among adolescents (O’Connor et al., 2007; Stone et al., 2012; Yu, Lombe, Nebbitt, Pitner, \& Salas-Wright, 2012), young adults (Borsari \& Carey, 2003), and the general population (Cochran, Grella, \& Mays, 2012). Simply, individuals reporting tolerant injunctive norms - that is, those who believe that the use of substances is socially acceptable - are much more likely to use substances than those who believe that such use is not socially approved.

While it is apparent how tolerant injunctive norms towards substance use might be related to adolescent substance use and abuse, the precise dynamics of how adolescents develop beliefs about substance use are less straightforward. In the social development model framework, Catalano and Hawkins (1996) suggest that socialization and social bonding leads to the development of pro- or antisocial beliefs around substance use. This basic framework is consistent with religiosity scholars' theories that suggest that moral beliefs emerge through the socialization of children and adolescents into the implicit and explicit social norms of religious 
PUBLIC OR PRIVATE RELIGIOSITY?

communities (King, 2003; King \& Roeser, 2009; Smith \& Denton, 2005). As such, it could be hypothesized that greater public and private religiosity are associated with the development of less tolerant injunctive substance use norms which, in turn, are associated with substance use.

\section{The Present Study}

While previous research has found that religiosity is associated with substance use among adolescents, this study advances our understanding by examining the ways in which these constructs are linked. The aim of this study is to examine the complexity of the relationships between religiosity, sensation seeking, injunctive norms, and adolescent substance use using a national data set, the National Survey on Drug Use and Health (NSDUH), to examine the role of public and private religiosity as factors that moderate the relationships between sensation seeking and injunctive norms, and the use of cigarettes, alcohol, and marijuana. This study examines three interrelated research questions: First, does religiosity buffer the relationship between key psychosocial risk factors and substance use? Second, is the relationship between religiosity and substance use primarily direct in nature or are there factors that mediate this association? Finally, do these moderated and mediated relationships vary in terms of the influence of public religious involvement versus the privately held religious views of youth? To this end, three hypotheses will be examined:

$\mathbf{H}_{1}$ : Public and private religiosity are associated with a decreased likelihood of adolescent cigarette, alcohol, and marijuana use.

H2. Public and private religiosity moderate the relationship between sensation seeking and adolescent substance use.

H3. Public and private religiosity moderate the relationship between tolerant injunctive substance use norms and adolescent substance use. 
PUBLIC OR PRIVATE RELIGIOSITY?

Additionally, this study also examines the role of injunctive norms as a mediating factor in the relationship between religiosity and substance use, as well as the interactive relationship between religiosity, sensation seeking, and substance use. Two hypotheses guide this component of the study:

H4. Tolerant injunctive substance use norms mediate the relationship between public and private religiosity and adolescent substance use.

H5. Tolerant injunctive norms towards substance use mediate the interactive relationship between sensation seeking and adolescent public and private religiosity.

\section{Method}

\section{Sample and Procedures}

This study is based on public-use data from the 2010 NSDUH (SAMHSA, 2011). The NSDUH is designed to provide population estimates of substance use and health-related behaviors in the U.S. general population. It utilizes multistage area probability sampling methods to select a representative sample of the U.S. civilian, non-institutionalized population aged 12 years or older for participation in the study. With respect to the NSDUH, all 50 states and the District of Columbia were included. Study participants include household residents; residents of shelters, rooming houses, and group homes; residents of Alaska and Hawaii; and civilians residing on military bases. To improve the precision of drug use estimates for subgroups, adolescents aged 12 to 17 years and young adults aged 18 to 25 years were oversampled.

NSDUH study participants were interviewed in private at their places of residence. Potential participants were assured that their names would not be recorded and that their responses would be kept strictly confidential. Participants were paid thirty dollars for their participation. The NSDUH interview utilizes a computer-assisted interviewing (CAI) 
PUBLIC OR PRIVATE RELIGIOSITY?

methodology to increase the likelihood of valid respondent reports of illicit substance use behaviors (SAMHSA, 2011). The CAI methodology includes a combination of computerassisted personal interviewing (CAPI) and audio computer-assisted self-interviewing (ACASI) methodologies. A more detailed description of the NSDUH sampling and data collection procedures are documented in greater detail elsewhere (SAMHSA, 2011).

A total of 68,487 respondents aged 12 years or older completed the 2010 survey. Weighted response rates were $88.8 \%$ for household screening and $74.7 \%$ for interviewing (SAMHSA, 2011). Each independent, cross-sectional NSDUH sample was considered representative of the U.S. general population aged 12 years or older. The current study restricted analyses to adolescents aged $12-17$ years $(\mathrm{N}=18,614)$. The mean age of the sample is 14.6 years old $(\mathrm{SD}=1.7)$. The respondents were evenly distributed between males $(51.0 \%)$ and females (49.0\%), but unevenly distributed in terms of race and ethnicity. More than half of the respondents are White (59.6\%), 17.6\% are Hispanic, and 13.4\% are African-American. The annual family income of $17.3 \%$ of the sample is less than $\$ 20,000,31.8 \%$ have income between $\$ 20,000$ and $\$ 49,999,18.6 \%$ have income between $\$ 50,000$ and $\$ 74,999$, and $32.3 \%$ have more than $\$ 75,000$ annual family income.

\section{Measures}

Substance use. Three substance use items assessed the frequency of tobacco, alcohol, and marijuana use in the previous 30 days. Respondents reported using the aforementioned substances on anywhere between 0 and 30 days during the previous 30 day period. Additionally, a dichotomous $(0=$ no use of any substances, $1=$ use of one or more substance $)$ measure of substance use was constructed by summing three dichotomous items measuring tobacco, alcohol, and marijuana use over the previous month. 
PUBLIC OR PRIVATE RELIGIOSITY?

Religiosity. Two measures of religiosity were examined in this study: public and private religiosity. Public religiosity was measured by asking respondents: "During the past 12 months, how many times did you attend religious services (excluding special occasions such as weddings, funerals, etc.)". Consistent with the original NSDUH coding scheme, youth were categorized into five ordinal groups ranging from no religious service attendance $(\mathrm{N}=6,262)$ to attendance at more than 52 religious services in the previous year $(\mathrm{N}=3,066)$. Private religiosity was assessed by summing two items measuring the degree to which respondents considered religious beliefs to be important to their life and decision making $(\alpha=.872)$. More precisely, these two items were measured by asking respondents the degree to which they agreed with the following statements: "Your religious beliefs are a very important part of your life" and "Your religious beliefs influence how you make decisions in your life." Both items had the response format of "strongly disagree", “disagree", "agree”, and "strongly agree" with higher scores indicating greater adolescent private religiosity. These measures of public and private religiosity are consistent with variables commonly used by scholars when assessing the protective effects of public and private religiosity (Desmond, Soper, Purpura, \& Smith, 2008; Hodge et al., 2011; Nonnemaker et al., 2003).

Sensation seeking. Sensation seeking was assessed by summing two items related to the frequency of adolescent enjoyment of participation in dangerous or risky behaviors $(\alpha=.81)$. These items measured the frequency of respondent agreement with the following statements, "How often do you get a real kick out of doing things that are a little dangerous?" and "How often do you like to test yourself by doing something a little risky?" Both items had the response format of "never", "seldom", or "sometimes or always" with higher scores indicating greater adolescent sensation seeking. 
PUBLIC OR PRIVATE RELIGIOSITY?

Injunctive norms. Injunctive norms were assessed by summing four items pertaining to the use of cigarettes, alcohol, and marijuana $(\alpha=.89)$. Sample items included, "How do you feel about someone your age trying marijuana or hashish once or twice?" and "How do you feel about someone your age having one or two drinks of an alcoholic beverage nearly every day?” Responses were recorded on a 3-point scale: $1=$ strongly disapprove, 2 = somewhat disapprove, or $3=$ neither approve nor disapprove.

Sociodemographic and mental health covariates. The following demographic variables were used: age, gender, race and ethnicity (non-Hispanic white, non-Hispanic black, Hispanic, and other [American Indian or Alaska Native, Asian, other Pacific Islander or Native Hawaiian, and persons reporting more than one race]), presence of father in home, school dropout status, and total annual family income (less than $\$ 20,000, \$ 20,000$ to $\$ 49,999, \$ 50,000$ to $\$ 74,999$, and $\$ 75,000$ or more). Additionally, we also controlled for lifetime history of depression and anxiety. Determination of lifetime depression and anxiety were self-reported and based on whether respondents were told by a doctor or medical professional that they had either of these disorders.

\section{Statistical Analysis}

For all analyses, weighted prevalence estimates and standard errors were computed using Stata 12.1SE (StataCorp, 2011). This system implements a Taylor series linearization to adjust standard errors of estimates for complex survey sampling design effects including clustered data.

Negative binomial regression (NBR). Two separate sets of analyses were conducted for this study. First, a series of NBR analyses were conducted in order to analyze the direct effects and interaction effects between the risk factors, religiosity, and frequency of substance use. This method was selected because preliminary data analyses revealed that the data for the frequency of cigarette, alcohol, and marijuana use were non-normally distributed with an extreme positive 


\section{PUBLIC OR PRIVATE RELIGIOSITY?}

skew (Long \& Freese, 2006). NBR was selected over Poisson regression as preliminary diagnostic analysis yielded evidence of overdispersion which suggests that NBR models were preferable to Poisson regression models (Hilbe, 2011).

To examine the moderating effect of religiosity, several sequential steps were taken. To begin, all continuous independent and moderating variables were standardized to reduce multicollinearity (Cohen, Cohen, West, \& Aiken, 2003). Next, the product (or interaction) terms were created by multiplying together the standardized independent and moderator variables. Finally, two sets of generalized linear regression analyses were conducted for each of the three dependent variables. First, NBR was conducted for the sociodemographic and risk and protective factors only. Next, an additional NBR was conducted with the sociodemographic variables, risk and protective factors, and the four interaction terms. Incidence rate ratios (IRR) and accompanying confidence intervals were estimated for both NBR analyses. Incidence rate ratios, conceptually similar to odds ratios, refer to the ratio of the enactment of a particular behavior, in this case substance use, given distinct conditions (Hilbe, 2011). This multistep regression process ensures that accurate and readily interpretable estimates are provided for both the main effects and the interaction effects (Frazier, Tix, \& Barron, 2004).

Path analysis. Path analysis was conducted to examine the direct and mediated relationships between public religiosity, private religiosity, sensation seeking, tolerant injunctive norms, and adolescent substance use. The virtue of path analysis is that it is a statistical technique that allows researchers to specify and test the goodness of fit between sample data and theoretical models designed to depict the causal relationships between observed variables (Kline, 2005). Although the data utilized in this study is cross-sectional and cannot be used to infer causal relationships, mediation analysis is used here in an exploratory correlational fashion. In 


\section{PUBLIC OR PRIVATE RELIGIOSITY?}

addition, when combined with other approaches, path analysis can be used to model interaction effects and other nonlinear effects (Little, Card, Bovaird, Preacher, \& Crandall, 2007;

Schumacker \& Lomax, 2010).

In order to examine the moderating effect of private religiosity and public religiosity on the relationship between sensation seeking and injunctive norms, multiplicative terms representative of the interactions between sensation seeking and private religiosity as well as sensation seeking and public religiosity were included in all preliminary models. Consistent with the NBR analyses, all continuous independent and moderating variables were standardized to reduce multicollinearity (Cohen et al., 2003). The items used in the moderation analysis (i.e. sensation seeking, private religiosity) were allowed to co-vary with one another and the interaction term. Exogenous factors found to be unrelated to the mediating and outcome variables were removed from the final analysis.

Multiple indicators can be useful in evaluating the goodness of fit of path models. First, the Chi-Square statistic, although strongly influenced by sample size and other factors (Kline, 2005), should have a value close to the number of degrees of freedom and a probability value greater than .05 (Schumaker \& Lomax, 2010). However, given the instability of the Chi-Square statistic, other measures such as the Root Mean Square Error of Approximation (RMSEA), Comparative Fit Index (CFI), and Tucker Lewis Index (TFI) should also be considered in determining goodness of fit (Byrne, 2001). Tran (2009) recommends that the RMSEA value be below .05 and no greater than .08 , and that the CFI and TFI should be above .90 .

\section{Results}

\section{Negative Binomial Regression}


PUBLIC OR PRIVATE RELIGIOSITY?

Table 1 displays results of negative binomial regression models examining the associations between sensation seeking, injunctive norms, public and private religiosity, and cigarette, alcohol, and marijuana use. Results at Step 1 lent support to Hypothesis 1 as both public and private religiosity were found to be consistently associated with substance use. More precisely, public religiosity was negatively associated with cigarette $(\mathrm{IRR}=0.73,95 \%$ C.I. $=$ 0.61-0.87) and marijuana use ( $\mathrm{IRR}=0.77, \mathrm{CI}=0.65-0.92)$, but not with the use of alcohol. Private religiosity, however, was negatively associated with all three manifestations of substance use behavior. Results also revealed that sensation seeking and tolerant injunctive norms towards substance use were both significantly associated with all manifestations of substance use examined in this study.

*** INSERT TABLE 1 ABOUT HERE ***

Results at Step 2 revealed several statistically significant interaction effects and lent differential support to Hypothesis 2 and Hypothesis 3. With respect to Hypothesis 2, the hypothesized moderating effect of religiosity on the relationship between sensation seeking and substance use was exclusively identified for the moderating effect of private religiosity in relation to marijuana use. As illustrated in Figure 2, among adolescents with low sensation seeking, marijuana use is only slightly greater among youth with low private religiosity than among youth with high private religiosity. However, when sensation seeking is high, marijuana use is disproportionately elevated among adolescents with low private religiosity as compared to those with high private religiosity.

\section{*** INSERT FIGURE 2 ABOUT HERE ***}

In terms of Hypothesis 3, the hypothesized moderating effect of religiosity on the relationship between tolerant injunctive norms and substance use was not identified for public 


\section{PUBLIC OR PRIVATE RELIGIOSITY?}

religiosity, but was identified for private religiosity in relation to all forms of substance use. Specifically, significant moderating effects were identified in terms of the ways in which private religiosity impacted the relationship between tolerant injunctive norms and the use of cigarettes, alcohol, and marijuana. Among adolescents who disapproved of adolescent substance use, the use of all substances was low even when private religiosity was low. However, among adolescents with more tolerant injunctive norms towards substance use, the use of cigarettes, alcohol, and marijuana was disproportionately elevated among adolescents who reported low private religiosity as compared to youth with higher levels of private religiosity. While all three of these interactions were found to be significant, the magnitude of this multiplicative relationship was greatest for marijuana use $(\mathrm{IRR}=1.33,95 \% \mathrm{CI}=1.14-1.56)$ followed by cigarette use $(I R R=1.18,95 \% \mathrm{CI}=1.02-1.35)$ and then alcohol use $(\mathrm{IRR}=1.12,95 \% \mathrm{C} . \mathrm{I} .=$ 1.02-1.23). Notably, public religiosity did not significantly moderate the relationship between either sensation seeking or injunctive norms and adolescent substance use.

\section{Path Analysis}

Figure 3 presents the path diagram for the relationship between private religiosity, public religiosity, sensation seeking, tolerant injunctive norms towards substance use, and adolescent substance use. The goodness of fit statistics for this model indicated acceptable model fit. The Chi-Square statistic, which is influenced by sample size, was significant $(\chi 2=84.04, \mathrm{df}=2, \mathrm{p}<$ .001 ); however, the RMSEA value of 0.49 , the CFI value of 0.98 , and the TLI value of 0.991 were all in the acceptable range of goodness of fit values. The multiplicative term between sensation seeking and public religiosity was not included in the final model as it was not found to be significantly associated to any of the specified endogenous variables. No problems were 
PUBLIC OR PRIVATE RELIGIOSITY?

identified in terms of model identification and no additional plausible model modifications were identified.

Results from the path analysis lent strong support to Hypothesis 4 and partial support to Hypothesis 5. With respect to Hypotheses 4, results suggested that tolerant injunctive norms mediated the relationship between public and private religiosity and substance use. Specifically, public religiosity was associated with tolerant injunctive norms $(\beta=-0.08, \mathrm{p}<.001)$, but no direct association could be identified between public religiosity and adolescent substance use. In contrast, private religiosity was directly associated with lower rates of adolescent substance use $(\beta=-0.13, p<.001)$. Private religiosity was also significantly associated with less tolerant injunctive norms $(\beta=-0.11, \mathrm{p}<.001)$ which, in turn, was associated with higher rates of adolescent substance use $(\beta=0.19, \mathrm{p}<.001)$. Results also lent partial support to Hypothesis 5 as, in addition to the direct and indirect associations between private religiosity and substance use, private religiosity was also found to significantly moderate the relationship between sensation seeking and tolerant injunctive norms $(\beta=-0.04, \mathrm{p}<.01)$ which, as mentioned above, was significantly associated with higher rates of adolescent substance use. No significant moderating relationship was identified for public religiosity and, therefore, this variable was not included in the final model. Sensation seeking was also found to be significantly associated with tolerant injunctive norms $(\beta=0.17, \mathrm{p}<.001)$ and directly associated with substance use $(\beta=0.22, \mathrm{p}<$ $.001)$.

*** INSERT FIGURE 3 ABOUT HERE ***

\section{Discussion}

This study is among the first to systematically disentangle the relationships between public and private religiosity, sensation seeking, injunctive norms, and substance use among 


\section{PUBLIC OR PRIVATE RELIGIOSITY?}

adolescents in the United States. While it is well understood that adolescent religiosity is associated with the use and abuse of licit and illicit substances, few studies have revealed the pathways through which religiosity buffers youth against involvement in such behavior. The results of the present analysis shed light onto this complex relationship. First, results indicate that private religiosity - and not public religiosity - has important implications in terms of moderating the relationship between key risk factors and the use of cigarettes, alcohol, and marijuana. Across the board, among adolescents who disapproved of adolescent substance use, substance use is low even when private religiosity is low. However, among youth with more lenient views on adolescent substance use, substance use is disproportionately elevated among adolescents with low private religiosity as compared to those with high private religiosity. That is, private religiosity effectively buffers against the risk factor of tolerant injunctive norms towards substance use for a variety of substance use behaviors. Notably, private religiosity also significantly interacted with sensation seeking in terms of the use of marijuana. In all, private religiosity seems to be a particularly important protective factor among adolescents who report permissive views on adolescent substance use and among those who are prone to sensation seeking.

In addition to the moderating effect of private religiosity on the relationship between risk and protective factors and adolescent substance use, important relationships were revealed in terms of the mediated relationship between religiosity and substance use. Path analysis findings indicated that tolerant injunctive norms mediated the relationship between private religiosity, public religiosity, and adolescent substance use. Notably, tolerant injunctive norms completely mediated the relationship between public religiosity and substance use. This suggests that the protective effect of participating in a religious community is not direct in nature, but rather may 


\section{PUBLIC OR PRIVATE RELIGIOSITY?}

be accounted for by means of the instilment of cognitive moral beliefs relating to the use of illicit substances. The relationship between private religiosity and substance use was only partially mediated by tolerant injunctive norms. This suggests that while a substantial proportion of the protective effect of private religiosity on substance use is accounted for by the beliefs held by adolescents around the use of substances, private religiosity nevertheless also exerts a direct protective effect on the use of substances. It should be noted, however, that the magnitude of the direct relationship between private religiosity and substance use was relatively small. Given the partial mediation finding, future studies should examine other potential mediators in the relationship between religiosity and adolescent substance use that were not examined in the current study such as self-efficacy. Additionally, private religiosity moderated the relationship between sensation seeking and tolerant injunctive norms. This finding indicates that the strength of the relationship between sensation seeking and tolerant injunctive norms was attenuated by high levels of private religiosity. Future studies might also examine the links between injunctive norms and youth involvement other non-religious communities that may serve to transmit beliefs about the use of substances (e.g. secular youth groups, parents). In all, private religiosity and, to a lesser degree, public religiosity, are related to tolerant injunctive norms which, in turn has important implications in terms of adolescent substance use.

This study supports findings of previous research that suggest that adolescent religiosity serves to moderate the relationship between key risk factors and the use of illicit substances (Bahr \& Hoffman, 2008; Button et al., 2010; Desmond et al., 2011; Fowler et al., 2008). However, in contrast with the majority of moderation analyses, this study extends the literature by examining the differential impact of both public and private religious involvement. This more specified analysis allowed for the identification of private religiosity, rather than public 


\section{PUBLIC OR PRIVATE RELIGIOSITY?}

religiosity, as a significant moderating factor in terms of the relationship between key risk factors and substance use. Notably, this finding was distinct from the findings of Fowler and colleagues (2008) who examined the moderating effect of both public and private religiosity on the relationship between exposure to community violence and substance use.

This study also provides support for the work of religiosity scholars who have examined tolerant injunctive norms toward substance use as a key mediating factor of the relationship between religiosity and substance use and other problem behaviors (D’Onofrio et al., 1999; Harris, 2011; Johnson et al., 2008; Kim, 2003). Notably, however, none of these aforementioned studies independently examined the relationship between public and private religiosity in relation to tolerant injunctive norms. As such, prior work has been unable to elucidate the nuances of the relationship between private religiosity, public religiosity, beliefs around substance use, and the use of illicit substances among adolescents. Given the differences in terms of magnitude, complete and partial mediation, and the moderation of key risk factors, the differentiation between these two concepts is both conceptually meaningful and empirically relevant.

\section{Study Assets and Limitations}

The current study has a number of strengths. The national representativeness of the sample provides greater confidence in terms of the generalizability of the findings, a limiting factor in many studies of religiosity and substance use among adolescents in the U.S. Additionally, the use of multiple data analytic techniques allows for a nuanced examination of the complex relationships between religiosity, risk factors, and adolescent substance use. In contrast to many studies that exclusively examine main effects, this study used moderation and moderated mediation analysis to examine both the ways in which religiosity interacts with key risk factors as well as the factors that account for the relationship between religiosity and 


\section{PUBLIC OR PRIVATE RELIGIOSITY?}

adolescent substance use. These statistical approaches allow for the examination of the more specific pathways and relationships between religiosity and substance use in ways that main effects analyses simply cannot.

Despite these strengths, findings from the current investigation should be interpreted in light of several limitations. First, the measures of adolescent religiosity were limited in important ways. Public religiosity was identified on the basis of a single-item measure. This limitation is noteworthy as religiosity scholars have raised concerns about the potential methodological shortcomings of such single-item measures in studying youth religiosity in relation to behavioral outcomes (Berry 2005; Rew \& Wong 2006). However, several recent studies of the validity of single-item and brief measures indicate that the psychometric properties of such measures may be acceptable for the study of religiosity and health-related issues (Dollinger \& Malmquist, 2009; Menec, Shooshtari, \& Lambert, 2007; Zimmerman et al., 2006). Additionally, the composite measure of private religiosity, while high in terms of face validity and internal consistency, was not a previously validated or standardized measure. Second, while recent studies have highlighted the importance of examining inter-religious and inter-denominational differences in the examination of the links between religiosity and behavior (e.g. Fischer, 2010; Marsiglia et al., 2005), the NSDUH does not collect data on specific religious denominations. Consequently, we were unable to test whether attendance/involvement in particular types of religious communities is more effective than others. Third, the assessment of adolescent substance use did not provide insight into the specific contexts for these behaviors such as the role of peer influence or parental supervision. Along the same lines, the NSDUH does not include variables that would allow for an examination of the links between religiosity and substance use while controlling for the effects of non-religious activities that may have implications for the 
PUBLIC OR PRIVATE RELIGIOSITY?

development of adolescent moral beliefs and behavior (e.g. youth groups, parental factors). Our inability to measure such factors raises questions about the potential for estimation bias that should be addressed in future research. Fourth, given that the study data are cross-sectional, causal conclusions regarding adolescent religiosity and substance use cannot be drawn. Along the same lines, while all moderation analyses in this study were interpreted in terms of the moderating effect of religiosity on the relationship between sensation seeking, tolerant injunctive norms, and substance use, these two-way interactions are, in fact, symmetrical and, as such, can also be interpreted in terms of the moderating effect of sensation seeking and tolerant injunctive norms on the relationship between religiosity and substance use. Another limitation is that the NSDUH relies on respondent recall and is therefore subject to under-reporting or over-reporting. This can potentially limit the validity of measures influenced by social desirability biases (Holden, 2010) such as religiosity and the participation in substance use behaviors. Finally, although the NSDUH is a nationally representative sample, it is uncertain the degree to which the exclusion of institutionalized individuals may have influenced study findings. Additional studies with enriched correctional or clinical samples may serve to further elucidate the links between religiosity and substance use.

\section{Conclusion}

Overall, the findings of the present study suggest that private religiosity is an important protective factor among adolescents who report permissive views on adolescent substance use and those who are prone to sensation seeking. Findings help to extend a growing body of literature that has begun to examine the complexities of the relationship between adolescent religiosity and substance use. While previous research has indicated an association between religiosity and the diminished probability of using substances among adolescents, this study 
PUBLIC OR PRIVATE RELIGIOSITY?

helps to illuminate the complex manner in which religiosity protects against substance use in the context of key risk factors. Future studies should examine how the relationship between private and public religiosity, tolerant injunctive norms, sensation seeking, and adolescent substance use varies by subgroups, such as gender and race/ethnicity, as such findings would improve our understanding of the role of religiosity in preventing or reducing adolescent substance use. These findings could inform substance use preventive intervention programs. 
PUBLIC OR PRIVATE RELIGIOSITY?

\section{References}

Allport, G. W., \& Ross, M. J. (1967). Personal religious orientation and prejudice. Journal of Personality and Social Psychology, 5(4), 432-443.

Bahr, S.J., \& Hoffman, J.P. (2008). Religiosity, peers, and adolescent drug use. Journal of Drug Issues, 38(3), 743-769.

Berry, D. (2005). Methodological pitfalls in the study of religiosity. Western Journal of Nursing Research, 27(5), 628-647.

Borsari, B., \& Carey, K.B. (2003). Descriptive and injunctive norms in college drinking: A metaanalytic integration. Journal of Studies on Alcohol, 64(3), 331-341.

Button, T.M.M., Hewitt, J.K., Rhee, S.H., Corley, R.P., \& Stallings, M.C. (2010). The moderating effect of religiosity on the genetic variants of problem alcohol use. Alcoholism: Clinical and Experimental Research, 34(9), 1619-1624.

Catalano, R.F., \& Hawkins, J.D. (1996). The social development model: A theory of antisocial behavior. Delinquency and crime (pp. 149-197). New York: Cambridge University Press.

Centers for Disease Control and Prevention (2010a). Trends in the prevalence of selected risk behaviors and obesity for all students: National YRBS: 1991-2009. Retrieved from http://www.cdc.gov/healthyyouth/yrbs/

Centers for Disease Control and Prevention (2010b). "Youth Risk Behavioral Surveillance United States, 2009.” Morbidity and Mortality Weekly Report 59(5): 1-146.

Cohen, J., Cohen, P., West, S.G., \& Aiken, L.S. (2003). Applied to multiple regression /correlation analysis in the behavioral sciences (Third Edition). Mahwah, NJ: Erlbaum. DeLisi, M., \& Vaughn, M.G. (2008). The Gottfredson-Hirschi critiques revisited: Reconciling 
PUBLIC OR PRIVATE RELIGIOSITY?

self-control theory, criminal careers, and career criminals. International Journal of Offender therapy and Comparative Criminology, 52, 520-537.

Desmond, S.A., Soper, S.E., Purpura, D.J., \& Smith, E. (2008). Religiosity, moral beliefs, and delinquency: Does the effect of religiosity on delinquency depend on moral beliefs? Sociological spectrum: Mid-South Sociological Association, 29(1), 51-71.

Desmond, S.A., Soper, S.E. \& Kraus, R. (2011). Religiosity, peers, and delinquency: Does religiosity reduce the effect of peers on delinquency? Sociological Spectrum: Mid-South Sociological Association, 31(6), 665-694.

D’Onofrio, B.M., Murrell, L., Eaves, L.J., McCullough, M.E., Landis, J.L., \& Maes, H.H. (1999). Adolescent religiousness and its influence on substance use: Preliminary findings from the mid-Atlantic school-age twin study. Twin Research, 2, 156-168.

Dollinger, S. J., \& Malmquist, D. (2009). Reliability and validity of a single-item self-reports: With special relevance to college students alcohol use, religiosity, study, and social life. The Journal of General Psychology, 136(3), 231-241.

Dunlop, S.M., \& Romer, D. (2010). Adolescent and young adult crash risk: Sensation seeking, substance use propensity and substance use behaviors. Journal of Adolescent Health, 46, 90-92.

Ellickson, P.L., Tucker, J.S., \& Klein, D.J. (2003). Ten-year perspective study of public health problems associated with early drinking. Pediatrics, 111(5), 949-955.

Fischer, B.E.U. (2010). To drink or not to drink: the role of religion and family in drinking patterns among emerging adults. (Unpublished doctoral dissertation). The University of Notre Dame, Notre Dame, Indiana.

Fowler, P.J., Ahmed, S.R., Tompsett, C.J., Jozefowicz-Simbeni, D.M.H. \& Toro, P.A. (2008). 
PUBLIC OR PRIVATE RELIGIOSITY?

Community violence and externalizing problems: Moderating effects of race and religiosity in emerging adulthood. Journal of Community Psychology, 36(7), 835-850.

Gandini, S., Botteri, E., Iodice, I., Boniol, M., Lowenfels, A.B., Maisonnueve, P., \& Boyle, P. (2008). Tobacco smoking and cancer: A meta-analysis. International Journal of Cancer, 122(1), 155-164.

Good, M. \& Willoughby, T. (2006). The role of spirituality versus religiosity and adolescent psychosocial adjustment. Journal of Youth and Adolescence, 35 (1), 41-55.

Hilbe, J.M. (2011). Negative binomial regression ( $2^{\text {nd }}$ ed). New York: Cambridge University Press.

Hirschi, T. (1969). Causes of delinquency. Berkeley, CA: University of California Press.

Hirschi, T., \& Stark, R. (1969). Hellfire and delinquency. Social Problems, 17(2), 202213.

Hodge, D.R., Marsiglia, F.F., \& Nieri, T. (2011). Religion and substance abuse among youth of Mexican heritage: A social capital perspective. Social Work Research, 35(3), 137-146.

Jacobus, J., Bava, S., Cohen-Zion, M., Mahmood, O., Tapert, S.F. (2009). Functional consequences of marijuana use in adolescents. Pharmacology, Biochemistry, and Behavior, 92, 559-565.

Johnson, T., Sheets, V., Kristeller, J. (2008). Identifying mediators of the relationship between religiousness/spirituality and alcohol use. Journal of Studies on Alcohol and Drugs, 69, 160-170.

Johnston, L. D., O’Malley, P. M., Bachman, J. G., \& Schulenberg, J. E. (2011). Monitoring the Future national results on adolescent drug use: Overview of key findings, 2010. Ann Arbor: Institute for Social Research, The University of Michigan. 


\section{PUBLIC OR PRIVATE RELIGIOSITY?}

Koenig, H. G., King, D., \& Carson, V. B. (2012). Handbook of religion and health (2nd ed.). New York: Oxford University Press.

Hardie, J.H., Pearce, L.D., \& Denton, M.L. (2013). The dynamics and correlates of religious service attendance in adolescence. Youth \& Society. Advance online publication. doi: $10.1177 / 0044118 X 13483777$

Harris, M.M. (2011). Exploring potential mediators of the relationship between adolescent religiosity and delinquency using the risk and resilience framework. (Unpublished doctoral dissertation). Ohio State University, Columbus, Ohio.

Hawkins, J.D., Catalano, R.F., \& Miller, J.Y. (1992). Risk and protective factors for alcohol and other drug problems in adolescence and early adulthood: Implications for substance use prevention. Psychological Bulletin, 112(1), 64-105.

Hittner, J.B., \& Swickert, R. (2006). Sensation seeking and alcohol use: A meta-analytic review. Addictive Behaviors, 31, 1383-1401.

Jang, S. J., \& Johnson, B. R. (2011). The effects of childhood exposure to drug users and religion on drug use in adolescence and young adulthood. Youth \& Society, 43(4), 1220-1245.

Kim, J. (2003). A structural equation modeling analysis of the effect of religion on adolescent delinquency within an elaborated theoretical model: The relationship after considering family, peer, school, and neighborhood influences. (Unpublished doctoral dissertation). The Ohio State University, Columbus, Ohio.

King, P. E. (2003). Religion and identity: The role of ideological, social, and spiritual contexts. Applied Developmental Science, 7, 196-203.

King, P.E. \& Roeser, R.W. (2009). Religion and spirituality in adolescent development. In R.M. Lerner \& L. Steinberg (Eds.), Handbook of adolescent psychology (pp. 
PUBLIC OR PRIVATE RELIGIOSITY?

435-478). Hoboken, NJ: John Wiley \& Sons, Inc.

Krug, E.G., Mercy, J.A., Dahlberg, L.L., \& Zwi, A.B. (2002). The world report on violence and health. The Lancet, 360, 1083-88.

Little, T.D., Card, N.A., Bovaird, J.A., Preacher, K.J., \& Crandall, C.S. (2007). Structural equation modeling of mediation and moderation with contextual factors. In T.D. Little, J.A. Bovaird, \& N.A. Card (Eds.), Modeling contextual effects in longitudinal studies (pp. 207-230). Mahwah, NJ: Lawrence Erlbaum Associates.

Longest, K.C., \& Vaisey, S. (2008). Control or conviction? Objective and subjective religiosity and adolescent marijuana use. Journal of Drug Issues, 38(3), 689-715.

Longshore, D., Chang, E., Hsieh, S-C, \& Messina, N. (2004). Self-control and social bonds: A combined control perspective on deviance. Crime \& Delinquency, 50, 542-564.

Marsiglia, F.F., Kulis, S., Nieri, T., Parsai, M. (2005). God forbid! Substance use among religious and nonreligious youth. American Journal of Orthopsychiatry, 75(4), 585-598.

McCullough, M.E., \& Willoughby, B.L.B. (2009). Religion, self-regulation, and self-control: Associations, explanations, and implications. Psychological Bulletin, 135(1), 29-93.

Menec, V. H., Shooshtari, S., \& Lambert, P. (2007). Ethnic differences in self-rated health among older adults. Journal of Aging and Health, 19(1), 62-86.

Nonnemaker, J.M., McNeely, C.A., \& Blum, R.W. (2003). Public and private domains of religiosity and adolescent health risk behaviors: Evidence from the National Longitudinal Study of Adolescent Health. Social Science \& Medicine, 57, 2049-2054.

O’Connor, R.M., Fite, P.J., Nowlin, P.R., \& Colder, C.R. (2007). Children's beliefs about substance use: An examination of age differences in implicit and explicit cognitive 
PUBLIC OR PRIVATE RELIGIOSITY?

precursors of substance use initiation. Psychology of Addictive Behaviors, 21(4), 525533.

Regnerus, M.D. (2003). Religion and positive adolescent outcomes: A review of research and theory. Review of Religious Research, 44(4), 394-413.

Rehm, J., Gmel, G., Sepos, C.T., Trevisan, M. (2003). Alcohol-related morbidity and mortality. Alcohol Research and Health, 27(1), 39-51.

Rew, L., \& Wong, Y.J. (2006). A systematic review of associations among religiosity/spirituality and adolescent health attitudes and behaviors. Journal of Adolescent Health, 38, 433442.

Salas-Wright, C.P., Hernandez, L., Maynard, B.R., Saltzman, L., \& Vaughn, M.G. (2014). Early alcohol use among Hispanic adolescents in the United States: An examination of behavioral risk and protective profiles. Substance Use and Misuse. Advance online publication. doi: 10.3109/10826084.2014.880725

Salas-Wright, C.P., Olate, R., \& Vaughn, M.G. (2013a). The protective effects of religious coping and spirituality on delinquency: Results among high-risk and gang-involved Salvadoran youth. Criminal Justice and Behavior, 40(9), 988-1008.

Salas-Wright, C.P., Olate, R., \& Vaughn, M. (2013b). Religious coping, spirituality, and substance use and abuse among youth in high-risk communities in San Salvador, El Salvador. Substance Use and Misuse, 48(9), 769-783.

Salas-Wright, C.P., Vaughn, M.G., Hodge, D.R., \& Perron, B.E. (2012). Religiosity profiles of American youth in relation to substance use, violence, and delinquency. Journal of Youth and Adolescence, 41(2), 1560-1575.

Schultz, P. W., Nolan, J. M., Cialdini, R. B., Goldstein, N. J., \& Griskevicius, V. (2007). The 
PUBLIC OR PRIVATE RELIGIOSITY?

constructive, destructive, and reconstructive power of social norms. Psychological Science, 18, 429-434.

Smith, C. (2003). Religious participation and network closure among American adolescents. Journal for the Scientific Study of Religion, 42(2), 259-267.

Smith, C., \& Denton, M.L. (2005). Soul-searching: The religious and spiritual lives of American teenagers. New York: Oxford University Press.

Smith, C., Faris, R., Denton, M.L., \& Regnerus, M. (2003). Mapping American adolescent subjective religiosity and attitudes of alienation toward religion: a research report. Sociology of Religion, 64(1), 111-133.

Stark, R. (1996). Religion as context: Hellfire and delinquency one more time. Sociology of Religion, 57(2), 163-173.

StataCorp. (2011). Stata Statistical Software: Release 12. College Station, TX: StataCorp LP.

Steinberg, L., Albert, D., Cauffman, E., Banich, M., Graham, S., \& Woolard, J. (2008). Age differences in sensation seeking and impulsivity as indexed by behavior and self-report: Evidence for a duel systems model. Developmental Psychology, 44(6), 1764-1778.

Stone, A.L., Becker, L.G., Huber, A.M., \& Catalano, R.F. (2012). Review of risk and protective factors of substance use and problem use in emerging adulthood. Addictive Behaviors, 37(7), 747-775.

Substance Abuse and Mental Health Services Administration, Office of Applied Studies (2011) Results from the 2010 National Survey on Drug Use and Health: National Findings. Rockville, MD: Substance Abuse and Mental Health Services Administration.

Ulmer, J.T., Desmond, S., Jang, S.J., \& Johnson, B.R. (2010). Teenage religiosity and changes in 
PUBLIC OR PRIVATE RELIGIOSITY?

marijuana use during the transition to adulthood. Interdisciplinary Journal of Research on Religion, 6, 1-19.

Ulmer, J.T., Desmond, S., Jang, S.J., \& Johnson, B.R. (2012). Religiosity and dynamics of marijuana use: Initiation, persistence, and desistence. Deviant Behavior, 33, 448-468.

Vaughn, M. G., Beaver, K. M., DeLisi, M., Perron, B. E., \& Schelbe, L. (2009). Gene-

environment interplay and the importance of self-control in predicting polydrug use and substance-related problems. Addictive Behaviors, 34, 112-116.

Vaughn, M. G., Freedenthal, S., Jenson, J. M., \& Howard, M. O. (2007). Psychiatric symptoms and substance use among juvenile offenders: A latent profile investigation. Criminal Justice and Behavior, 34, 1296-1312.

Vaughn, M.G., Salas-Wright, C.P., \& Maynard, B.R. (2013). Drug abuse and addiction careers: A cell to society perspective. In B. Boutwell, K. Beaver, \& J.C. Barnes (Eds.), The Nurture versus Biosocial Debate in Criminology. Thousand Oaks, CA: Sage Publications.

White, H.R., Loeber, R., \& Farrington, D.P. (2008). Substance use, drug dealing, gang membership, and the gun carrying and their predictive associations with serious violence and serious theft. In R. Loeber, D.P. Farrington, M. Stouthamer-Loeber, \& H.R. White (Eds.), Violence and serious theft: Development and prediction from childhood to adulthood (pp. 137-166). New York: Routledge.

Wills, T. A., Sandy, J. M., \& Yaeger, A. M. (2002). Moderators of the relation between substance use level and problems: Test of a self-regulation model in middle adolescence. Journal of Abnormal Psychology, 111, 3-21.

Yonker, J.E., Schnabelrauch, C.A., \& DeHaan, L.G. (2012). The relationship between 


\section{PUBLIC OR PRIVATE RELIGIOSITY?}

spirituality and religiosity on psychological outcomes in adolescents and emerging adults: A meta-analytic review. Journal of Adolescence, 35, 299-314.

Yu, M., Lombe, M. Nebbitt, V.E., Pitner, R., \& Salas-Wright, C.P. (2012). Understanding tobacco use among African American adolescents living in urban public housing communities: A test of problem behavior theory. Addictive Behaviors, 37(8), 978-981.

Zimmerman, M., Ruggero, C. J., Chelminski, I., Young, D., Posternak, M. A., Friedman, M. et al. (2006). Developing brief scales for use in clinical practice: The reliability and validity of single-item self-report measures of depression symptom severity, psychosocial impairment due to depression, and quality of life. Journal of Clinical Psychiatry, 67(10), 1536-1541.

Zuckerman, M. (1979). Sensation seeking: Beyond the optimal level of arousal. Hillsdale, Erlbaum.

Zuckerman, M. (1994). Behavioral expressions and biosocial bases of sensation seeking. Cambridge: Cambridge University Press. 
PUBLIC OR PRIVATE RELIGIOSITY?

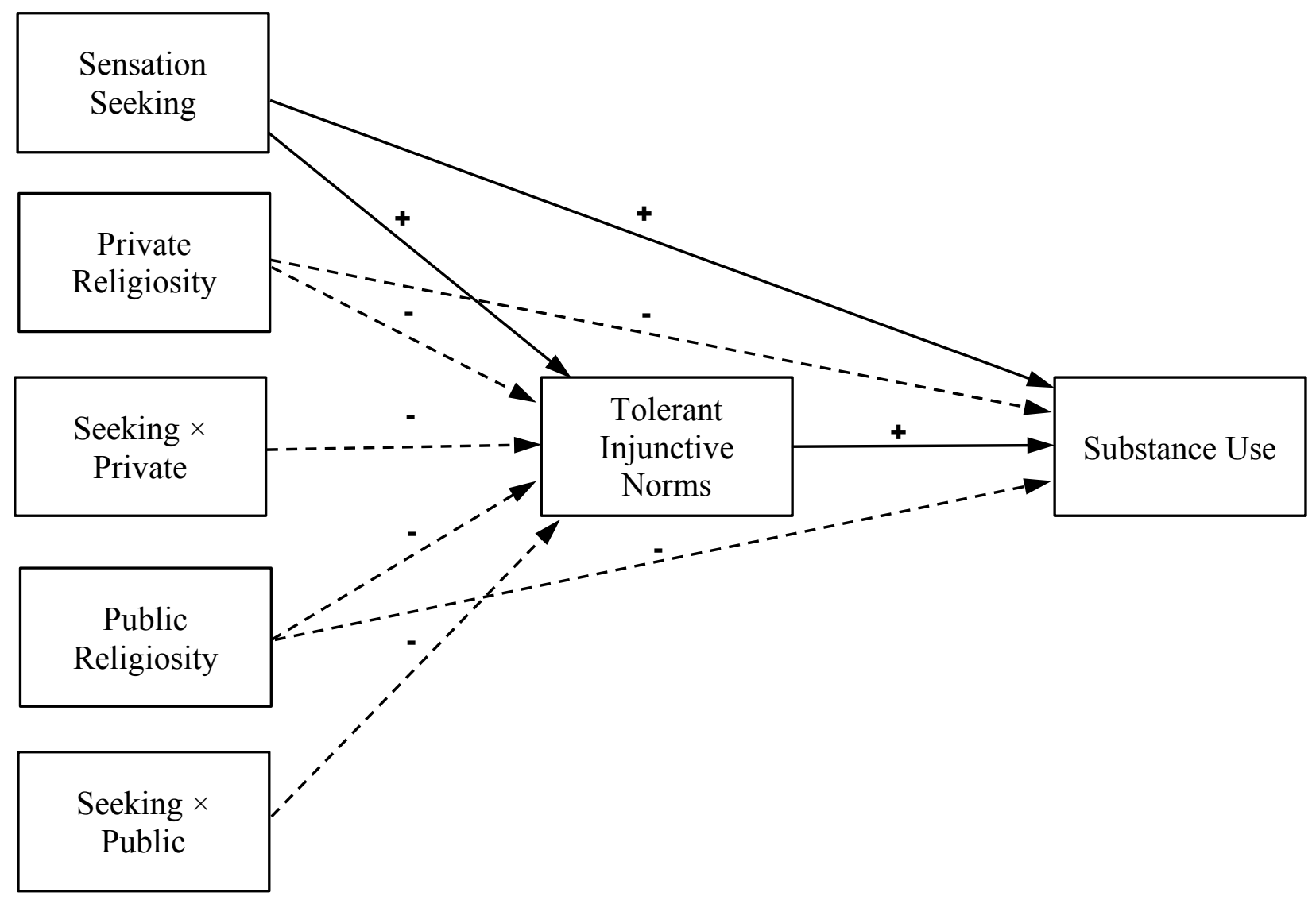

Figure 1. Hypothesized mediated and direct effects between private and public religiosity, sensation seeking, tolerant injunctive norms, and substance use. 


\section{Table 1}

Main and moderating effects of religiosity on the association between key risk factors and the frequency of adolescent substance use during the previous 30 days.

\begin{tabular}{|c|c|c|c|c|c|c|}
\hline & \multicolumn{2}{|c|}{ Cigarettes } & \multicolumn{2}{|c|}{ Alcohol } & \multicolumn{2}{|c|}{ Marijuana } \\
\hline & IRR & 95\% C.I. & IRR & 95\% C.I. & IRR & 95\% C.I. \\
\hline \multicolumn{7}{|l|}{ Step One } \\
\hline \multicolumn{7}{|l|}{ Sociodemographic Variables } \\
\hline Age & 1.79 & (1.64-1.95) & 1.60 & $(1.51-1.69)$ & 1.83 & $(1.66-2.01)$ \\
\hline Male & 1.19 & $(0.91-1.56)$ & 0.80 & $(0.68-0.96)$ & 1.36 & (1.01-1.83) \\
\hline \multicolumn{7}{|l|}{ Race/Ethnicity } \\
\hline African American & 0.74 & $(0.35-1.55)$ & 1.14 & $(0.78-1.67)$ & 2.27 & $(1.18-4.38)$ \\
\hline Hispanic & 0.82 & $(0.53-1.28)$ & 1.09 & $(0.87-1.37)$ & 0.88 & $(0.63-1.24)$ \\
\hline Other & 0.89 & $(0.55-1.44)$ & 0.76 & $(0.50-1.14)$ & 0.96 & $(0.54-1.70)$ \\
\hline \multicolumn{7}{|l|}{ Family Income } \\
\hline$<\$ 20,000$ & 3.46 & $(2.23-5.37)$ & 1.04 & $(0.68-1.57)$ & 1.90 & $(1.19-3.02)$ \\
\hline$\$ 20,000-\$ 49,000$ & 2.47 & $(1.74-3.52)$ & 1.00 & $(0.80-1.25)$ & 1.20 & $(0.80-1.79)$ \\
\hline$\$ 50,000-\$ 74,000$ & 1.66 & $(1.03-2.67)$ & 1.06 & $(0.84-1.35)$ & 0.94 & $(0.58-1.53)$ \\
\hline No Father in Home & 1.00 & $(0.72-1.40)$ & 0.97 & $(0.75-1.27)$ & 1.00 & $(0.73-1.36)$ \\
\hline Dropped Out of School & 0.70 & $(0.44-1.10)$ & 0.50 & $(0.30-0.85)$ & 0.54 & $(0.31-0.95)$ \\
\hline Lifetime Depression & 3.35 & $(2.22-5.05)$ & 1.58 & $(1.04-2.40)$ & 2.03 & $(1.11-3.70)$ \\
\hline Lifetime Anxiety & 1.31 & $(0.86-1.99)$ & 0.95 & $(0.70-1.30)$ & 2.25 & $(0.86-5.83)$ \\
\hline \multicolumn{7}{|l|}{ Key Risk Factors and Religiosity } \\
\hline Sensation Seeking & 1.73 & $(1.47-2.04)$ & 1.70 & (1.54-1.87) & 1.83 & $(1.58-2.12)$ \\
\hline Tolerant Injunctive Norms & 2.86 & $(2.44-3.22)$ & 1.92 & $(1.75-2.08)$ & 3.33 & $(2.89-3.85)$ \\
\hline Public Religiosity & 0.73 & $(0.61-0.87)$ & 0.88 & $(0.77-1.00)$ & 0.77 & $(0.65-0.92)$ \\
\hline Private Religiosity & 0.76 & $(0.62-0.93)$ & 0.85 & $(0.76-0.95)$ & 0.69 & $(0.57-0.83)$ \\
\hline \multicolumn{7}{|l|}{ Step Two } \\
\hline \multicolumn{7}{|l|}{ Interaction Effects } \\
\hline Seeking $\times$ Public & 0.90 & $(0.74-1.10)$ & 0.94 & $(0.81-1.09)$ & 0.91 & $(0.77-1.07)$ \\
\hline Seeking $\times$ Private & 1.13 & $(0.96-1.34)$ & 0.95 & $(0.86-1.05)$ & 1.21 & $(1.02-1.42)$ \\
\hline Tolerant Norm $\times$ Public & 1.09 & $(0.93-1.27)$ & 0.99 & $(0.88-1.10)$ & 0.93 & $(0.80-1.10)$ \\
\hline Tolerant Norm $\times$ Private & 1.18 & $(1.02-1.35)$ & 1.12 & $(1.02-1.23)$ & 1.33 & (1.14-1.56) \\
\hline
\end{tabular}

Note: Incidence rate ratios in bold are statistically significant. 


\section{PUBLIC OR PRIVATE RELIGIOSITY?}

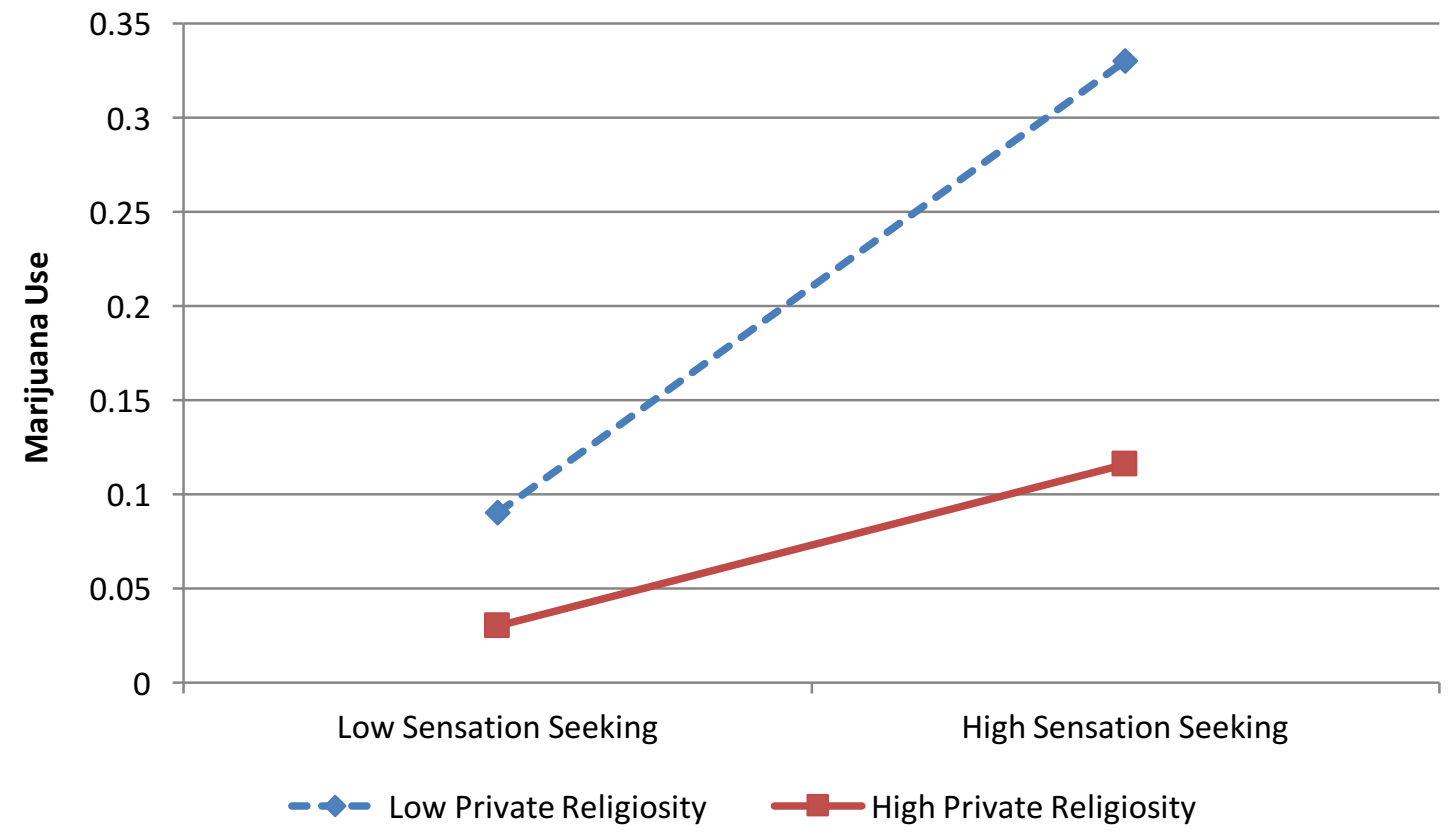

Figure 2. Private religiosity as a moderator of sensation seeking and marijuana use 


\section{PUBLIC OR PRIVATE RELIGIOSITY?}

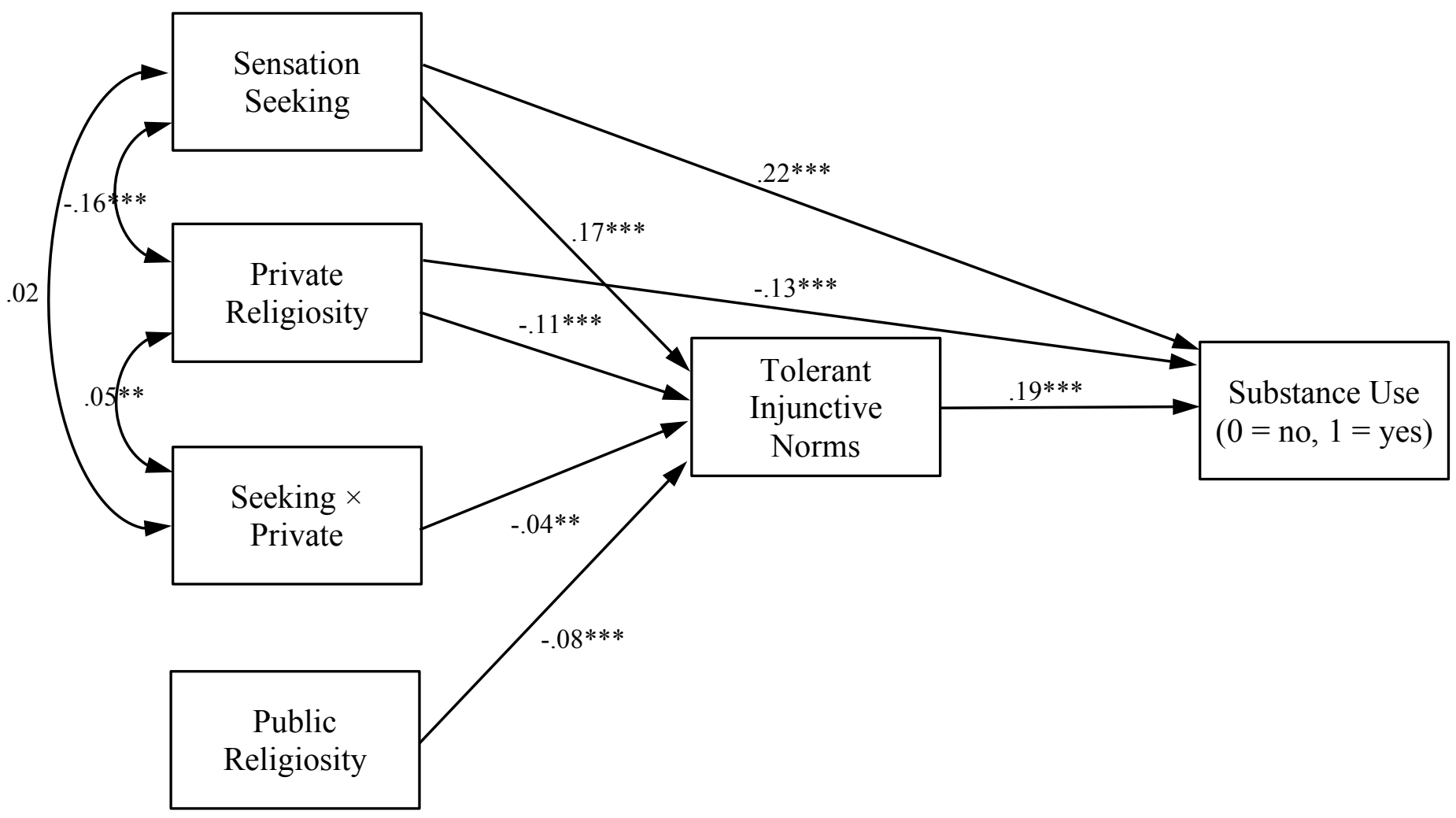

Figure 3. Path diagram for the moderated mediation model $(\mathrm{N}=17,621)$.

Note: $\chi^{2}=84.04, d f=2, p<.001 . \mathrm{CFI}=0.980, \mathrm{TLI}=0.911, \mathrm{RMSEA}=.049$.

$* \mathrm{p}<.05, * * \mathrm{p}<.01, * * * \mathrm{p}<.001$ 